\title{
Reprodução e dinâmica de \\ população em Synoeca surinama (Hymenoptera: Vespidae) (*)
}

\author{
E. G. Castellón ( $\left.{ }^{* *}\right)$
}

\section{Resumo}

Săo apresentados dados sobre a produção de ma chos, fêmeas e imaturos de primeira e segunda geração, e análises de ninhos deficitários quanto ao número de eclodidos, indicando uma possível migraçăo ou formaçăo de enxames periódicos. Evidências de ciclos monogínicos-poligínicos são aqui discutidas. Estes temas abordados, fazem parte de uma série de estratégias alternativas adotadas pela espécie $\mathbf{S}$. surinama pará assegurar e garantir que a produçăo de novos indivíduos e sua disseminação tenham sucesso, em resposta à pressão exercida pelos predadores, parasitas e o meio ambiente, assegurando assim, a sobrevivência da espécie.

\section{INTRODUÇĀO}

Embora seja conhecido que em Polybiini a formação de enxames (pleometrosis ou poliginía) è característica, as causas, coordenação das vespas, composição durante as mesmas e fatores reprodutivos são pouco conhecidos.

É possível que exista uma correlação entre a população inicial funđadora do ninho e a população final das vespas, com estágios intermediários, como resultado de fatores intrínsecos da própria colônia além das pressões ambientais.

Este estudo sobre a população dos ninhos de Synoeca surinama L. tem como objetivo esclarecer e apontar evidências sobre o processo de reprodução, acasalamento, produtividade e regulação do ciclo das colônias de S. surinama.

\section{MÉToDos}

O estudo foi realizado na Fazerida Taperinha $\left(02^{\circ} 25^{\prime} \mathrm{S}, 54^{\circ} 25^{\prime} \mathrm{W}\right)$ e Maicuru $\left(02^{\circ} 20^{\prime} \mathrm{S}\right.$, $\left.54^{\circ} 20^{\prime} \mathrm{W}\right)$ no estado do Pará-Brasil.

Foram coletados 26 ninhos com colônias, incluídos os imaturos, se presentes.

Para coletar cada colônia, foi colocado um pedaço de algodão embebido de clorofórmio na abertura de acesso ao ninho, posteriormente serrava o gaiho-substrato, coletando-se o ninho e a colônia conjuntamente, a coleta de ninhos com colônias se realizava à noite, quando toda a população de adultos encontrava-se no ninho.

Para realizar algumas observações, foram marcadas algumas vespas com tinta acrilex no noto do tórax.

O método de dissecção seguido para os indivíduos da colônia é o método rápido parcial de West-Eberhard (1975). Todos os indivíduos adultos coletados e que faziam parte das colônias foram dissecados. O reconhecimento dos machos em estado de pupa foi feito por contagem do número de segmentos abdominais. Pode-se, assim, diferenciar machos e fêmeas em estágio de pupas maduras e com apêndices desenvolvidos, como também em estágio adulto. As pupas machos e maduras e adultos machos apresentam sete segmentos abdominais enquanto que as fêmeas apresentam apenas seis segmentos abdominais. $O$ número de segmentos antenais dos machos é de 13 , enquanto que as fêmeas apresentam apenas 12 segmentos antenais.

As reprodutoras foram diferenciadas das operárias pela presença de ovários bem desenvolvidos.

\section{Resultados}

ovoposição

Depois da chegada de um enxame a um novo local de nidificação e de formadas as primeiras células-base, saem as rainhas do grupo de vespas.

Estas rainhas iniciam a ovoposição pelas células-base, acompanhadas de outras operárias que as protegem. As operárias acompanhantes variam em rúmero ac redor da rainha.

\footnotetext{
(*) - Trabalho realizado pelo projeto Pós-Graduação CNPq-INPA.

$(\bullet)$ - Instituto Nacional de Pesquisas da Amazônia, Manaus.
} 
Pode observar-se entre 10 a 25 acompanhantes por uma rainha. As rainhas podem, algumas vezes, estar desprotegidas porém, emi geral, não é o caso comum e outras operárias acompanhantes encontram-se ao redor. Para ovopositar, as rainhas caminham lentamente sobre as células-base introduzindo a cabeça e, com as antenas no interior das células, fazem um reconhecimento. Se uma célula-base encontra-se vazia geralmente, quase de imediato, a rainha dispõe-se a ovopositar, e introduz os últimos segmentos abdominais no interior da célula-base. Segundo Spradbery (1965), o mesmo comportamento ocorre em Vespula e Polistes. Simões (1977) o reporta em Stelopolybia pallipes (Oliv.) .

O tempo da ovoposição foi em S. surinama de 3 minutos. Akre et al. (1976), Spradbery (1965) e Simões (1977) dão as médias para outras espécies de vespas sociais. Observou-se nos ninhos 19 a 29 durante 5 dias, a ovoposição exercida pelas rainhas. Em determinados períodos, pode haver ovoposição por 2 até 5 rainhas. Simultaneamente, alguma rainha marcada podia reagrupar-se com outras operárias, sendo substituídas por outra rainha. Num ninho de Polybia sericea (Oliv.) em construção, foi possível observar rainhas marcadas que saiam de um grupo formado por outras rainhas e operárias, ovopositavam e voltavam a reagrupar-se posteriormente.

Já havendo ovopositado, a rainha de S. surinama posta-se com a cabeça na entrada da célula-base para dar proteção ao ovo. Este período de vigilância varia entre 20 a 30 minutos, ao cabo dos quais a rainha se retira e se dirige à outra célula-base. Imediatamente depois que a rainha se retira, algumas operárias acompanhantes começam a aumentar as paredes da célula-base acrescentando polpa.

Para que as paredes das células-base sejam elevadas além do nível inicial de construção $(1,9-2,8 \mathrm{~mm})$, é preciso um estímulo para as operárias. Inicialmente, este estímulo é possivelmente dado pela presença do ovo ovopositado e, posteriormente, pelo crescimento da larva, até chegar a um máximo de altura que corresponde ao tamanho das larvas de último estágio. De acordo com Deleurance (1950 apud
Jeanne, 1972), as células vazias estimulam a ovoposição em Polistes.

Durante a construção do ninho, a rainha ovoposita sem que existam células-base propriamente ditas. Depois de emergir o adulto, a célula já com paredes levantadas pode ser novamente ovopositada sem que as operárias elevem mais as paredes da célula.

Os ninhos de $S$. surinama aqui analisados não mostram indícios de que as células foram avopositadas mais de duas vezes. Ricnards \& Richards (1951) mencionam que em especies como Polybia rejecta (Fab.) as células podem ser reovopositadas duas ou mais vezes.

A posição dos ovos nas células e célulasbase está sempre no ângulo superior, onde convergem os dois lados superiores da célula, podendo estar também colocados na parte lateral destas paredes. A rainha, ao ovopositar, comumente orienta os ovos seguindo uma mes. ma direção e com o sentido da gravidade. Em Vespula atropilosa (Sladen), os ovos são colocados entre os lados e a parte central da câmara (Akre et al., 1976) .

Em alguns casos, numa mesma fileira de células ou células-base encontram-se ovos que não seguem a mesma orientação dos demais; isto sugere que, no momento da ovoposição, a rainha coloca o abdome em outra direção provocando uma alteração na disposição e orientação do ovo. Esta alteração na orientação do ovo não prejudica seu desenvolvimento nem o desenvolvimento das larvas dos prpimeiros estágios. Geralmente, em larvas do terceiro estágio, há uma reacomodação e ocupam quase a totalidade da célula com seu tamanho.

\section{REPRODUTORAS}

Das 6.046 fêmeas dissecadas, não se encontrou nenhuma que tivesse ovários semidesenvolvidos que fornecesse indícios de ovoposição ou a regressão dos ovários; sendo que as fêmeas com os ovários desenvolvidos apresentavam-se de uma forma bem caracterizada com a presença de oócitos. Jeanne (com. pessoal), ao dissecar uma colônia de $S$. surinama, encontrou quatro rainhas com espermatozóides na espermateca e 71 fêmeas com ovários não de- 
senvolvidos. Os diferentes tipos de ovários estão desenhados em Gobbi (1975) e Simões (1977) .

Em Polybiini uma fêmea apresenta dois avários e cada um é formado de três ovavríolos o que totaliza 6 ovaríolos em cada fêmea. O número de oócitos, em cada fêmea fértil, pode variar de acordo com a idade da rainha e com a maturação da colônia (West-Eberhard, 1973) .

$\mathrm{Na}$ tabela 1, pode ver-se o número de rainha por ninho, a média de oócitos por ovário por uma rainha a média de oócitos por ovaríolo por rainha e a idade período estimada.

A média de óocitos por ovários por uma rainha acha-se ao somar-se o número de oócitos rios ovários de cada rainha, dividindo logo o resultado entre o número de rainhas no ninho. A média de oócitos por ovaríolos se obteve, ao dividir-se a média de oócitos por ovários por uma rainha entre seis.

Observa-se, na tabela 1, que na colônia do ninho 20 não se encontrou rainha e nas colônias dos ninhos $26,40,44$ e 45 foi encontrada somente uma rainha.

Tradicionalmente, têm-se definido as espécies de Polybiini que formam ninhos por enxames e com a presença de mais de uma rainha fecundada que põe ovos como "pleiométricas" ou "poligínicas", ao contrário das espécies denominadas "haplometricas" ou "monogínicas" em que uma fêmea inicia o ciclo do ninho (Richards \& Richards, 1951; West-Eberhard, 1973; Gobbi, 1975) .

West-Eberhard (1973) encontrou espécies de Polybiini em que se misturam estes dois fatores denominando o cáso como polıginia temporal ou monoginia periódica. No seu trabalho, com Metapolybia docilis e M. aztecoides, WestEberhard (1973) achou que o enxame destas espécies pode ser formado por muitas operárias e a presençá de uma ou várias rainhas. Richards \& Richards (1951) também relataram vários ninhos de cinco espécies diferentes de vespas (Metapolybia cingulata (F.), Polybia micans (Ducke), P. bistriata (F.), P. bicyttarella (Rich.) e $P$. catillifex (Moeb.) cujas colônias apresentavam uma rainha no ninho. S. surinama apresenta este mesmo fenômeno durante o ciclo da colônia, no qual uma rainha chega com o enxame (veja ninho 45,1 rainha e com a idade período estimada em 0,21 ) ou várias rainhas. poliginia (Veja tabeia 7, onde se analisaram por dissecção 93 fêmeas capturadas e que formavam um enxame) - que durante um período ovopositaram um grande número de ovos para posteriormente permanecer só uma rainha Moncginia periódica - (veja ninhos 20, 40, 44, IPE $=0,67 ; 1,77$ e 1,73 , respectivamente) até chegar novamente a um estágio em que se encontram várias rainhas no ninho.

TABELA 1 - Número das rainhas por ninho, média de oócitos por ovário por rainhas, média dos oćcitos por ovaríolo por rainhas e idadeperíodo estimado para cada ninho. A idade-período foi calculada, conforme a fórmula de Richards \& Richards (1951).

\begin{tabular}{|c|c|c|c|c|}
\hline Ninho & $\begin{array}{l}\text { Rainha } \\
\text { no ninho }\end{array}$ & $\begin{array}{c}\text { Oócitos por } \\
\text { ovário }\end{array}$ & $\begin{array}{c}\text { Oócitos por } \\
\text { ováriolo }\end{array}$ & $\begin{array}{c}\text { Idade período } \\
\text { estimada }\end{array}$ \\
\hline 8 & 16 & 57,37 & 9,56 & 1,75 \\
\hline 19 & 28 & 46,50 & 7,75 & 0,46 \\
\hline 20 & 0 & 0 & 0 & 1,67 \\
\hline 21 & 15 & 40,00 & 6,66 & 1,70 \\
\hline 22 & 7 & 56,57 & 9,42 & 1,75 \\
\hline 23 & 19 & 49,89 & 8,31 & 1,60 \\
\hline 24 & 2 & 48,00 & 8,00 & 1,75 \\
\hline 25 & 15 & 51,60 & 8,60 & 1,79 \\
\hline 26 & 1 & 72,00 & 12,00 & 0,66 \\
\hline 27 & 21 & 50,57 & 8,42 & 1,72 \\
\hline 28 & 59 & 44,23 & 7,37 & 1.79 \\
\hline 29 & 33 & 42,18 & 7,03 & 0,39 \\
\hline 30 & 7 & 42,85 & 7,14 & 1,72 \\
\hline 31 & 25 & 41,52 & 6,92 & 0,84 \\
\hline 32 & 14 & 47,57 & 7,92 & 0,70 \\
\hline 33 & 19 & 43,26 & 7,21 & 0,67 \\
\hline 34 & 43 & 41,02 & 6,83 & 1,76 \\
\hline 36 & 8 & 51,75 & 8,62 & 1,69 \\
\hline 37 & 15 & 48,00 & 8,00 & 1,70 \\
\hline 38 & 14 & 63,85 & 10,64 & 1,78 \\
\hline 39 & 4 & 73,50 & 12,25 & 1,75 \\
\hline 40 & 1 & 48,00 & 8,00 & 1,77 \\
\hline 41 & 26 & 44,07 & 7,34 & 1,63 \\
\hline 43 & 4 & 43,50 & 7,25 & 0,47 \\
\hline 44 & 1 & 48,00 & 8,00 & 1,73 \\
\hline 45 & 1 & 48,00 & 8,00 & 0,21 \\
\hline Enxame & e 16 & 45,37 & 7,56 & 0,00 \\
\hline
\end{tabular}


A análise de correlação de Spearmann (Sokal \& Rohlf, 1969), entre a idade período estimado dos ninhos com o número de rainhas. deu um resultado não significativo. Este resultado sugere que não existe associação periódica fixa entre as variáveis e que o número de rainhas está condicionado ao regulamento intrínseco do ciclo da colônia.

\section{A POPULAÇÃo DO NINHO}

\section{Adultos}

Os dados dos 26 ninhos de S. surinama coletados com a sua população total de adultos encontram-se relacionados na tabela 2 . A população de adultos nos ninhos consiste de rainhas ou reprodutoras (ver tabela 1), machos (ver tabeia 6) e operárias. Operárias velhas correspondem juntamente com as rainhas fundadoras, às pioneiras na fundação do ninho, e as operárias jovens correspondem aos adultos produzidos recentemente nos ninhos onde houve emergência de adultos. Por ser realizada a coleta dos ninhos durante a noite, toda a população dos adultos foi capturada. Para cada ninhc se deduz que quando as células apresentam restos de mecônio ou seda, houve eclosão de adultos.

A tabela 2 evidencia que, em 9 ninhos $(34,60 \%)$, o número de emergidos é maior que a população total de adultos, enquanto que em outros 9 diferentes ninhos $(34,6 \%)$, a população de adultos foi maior que o número dos adultos emergidos. Em 8 ninhos $(30,8 \%)$, não

TABELA 2 - População das operárias e emergidos nos 26 ninhos de S. surinama. Operárias jovens apresentam intestino de cor branca face ao ácido úrico depositado. Operárias velhas não apresentam ácido úrico depositado no intestino, a cor deste é parda ou parda escura.

\begin{tabular}{|c|c|c|c|c|c|c|}
\hline Ninho & $\begin{array}{l}\text { Operárias } \\
\text { velhas }\end{array}$ & $\begin{array}{l}\text { Operárias } \\
\text { jovens }\end{array}$ & $\begin{array}{c}\text { Total } \\
\text { operárias }\end{array}$ & $\begin{array}{l}\text { Total dos } \\
\text { adultos }\end{array}$ & Emergidos & $\begin{array}{c}\text { Porcentagem } \\
\text { deficitária } \\
\text { dos emergidos }\end{array}$ \\
\hline 8 & 172 & 81 & 253 & 269 & 540 & 50,19 \\
\hline 19 & 181 & 0 & 181 & 209 & 0 & - \\
\hline 20 & 0 & 12 & 12 & 12 & 89 & 86,52 \\
\hline 21 & 118 & 16 & 234 & 149 & 232 & 35,80 \\
\hline 22 & 131 & 13 & 144 & 151 & 83 & - \\
\hline 23 & 357 & 18 & 375 & 415 & 875 & 52,60 \\
\hline 24 & 16 & 0 & 16 & 18 & 142 & 87,30 \\
\hline 25 & 47 & 89 & 136 & 151 & 118 & - \\
\hline 26 & 145 & 0 & 145 & 146 & 0 & - \\
\hline 27 & 293 & 26 & 319 & 340 & 263 & - \\
\hline 28 & 147 & 28 & 175 & 235 & 147 & - \\
\hline 29 & 196 & 0 & 196 & 229 & 0 & - \\
\hline 30 & 210 & 51 & 261 & 268 & 216 & - \\
\hline 31 & 135 & 0 & 135 & 160 & 0 & - \\
\hline 32 & 192 & 0 & 192 & 206 & 0 & - \\
\hline 33 & 307 & 0 & 307 & 326 & 0 & - \\
\hline 34 & 771 & 47 & 818 & 861 & 659 & - \\
\hline 36 & 224 & 16 & 240 & 255 & 554 & 54,00 \\
\hline 37 & 254 & 0 & 254 & 269 & 3 & - \\
\hline 38 & 438 & 115 & 553 & 614 & 427 & - \\
\hline 39 & 162 & 23 & 195 & 189 & 197 & 4,00 \\
\hline 40 & 78 & 3 & 81 & 82 & 5 & - \\
\hline 41 & 92 & 11 & 103 & 129 & 159 & 18,87 \\
\hline 43 & 228 & 0 & 228 & 232 & 0 & - \\
\hline 44 & 83 & 0 & 89 & 91 & 143 & 36,40 \\
\hline 45 & 117 & 0 & 117 & 118 & 0 & - \\
\hline
\end{tabular}


houve emergência de adultos, indicando a imaturação do ninho e evidenciando que possivelmente a população de adultos achados toi a inicial que formou o enxame e fundou o ninho.

Se forem analisadas as quantidades correspondentes nas colunas, emergidos e população total, evidencia-se o deficit de emergidos que corresponde à porcentagem na colura do mesmo nome na tabela 2. Duas alternativas podem apresentar-se para considerar a falta de indivíduos nos 9 ninhos: a) mortalidade alta devida aos predadores de adultos e ao declínio das operárias mais velhas; e b) abandono do ninho pela formação de enxames, deixando parte da população no ninho.

Não existem observações com respeito ao número de adultos produzidos ou emergidos $\mathrm{e}$ o número total de operárias e reprodutoras nos ninhos de Polybiini. Análises de correlação de Spearmann (Sokal \& Rohlf, 1969) para achar a associação entre estas variáveis em ninhos de S. surinama deram os seguintes resultados: número de operárias e número de emergidos $r_{\mathrm{s}}=0,40 ; 0,01>p>0,05$ e o número de operárias e o número de rainhas nos ninhos $r_{\mathrm{s}}=$ 0,$452 ; 0,01>p>0,05$.

Estes resultados confirmam que a população de operárias e as reprodutoras nos ninhos estão relacionadas assim como a produção de novos adultos com a população de operárias existentes nos ninhos. É possível que a produtividade dos ninhos esteja relacionada com a população de operárias e reprodutoras, onde os novos adultos de cada ninho substituem proporcionalmente a população de adultos mais velhos seja pelo declínio ou incapacidade reprodutora dessa população, seja pela migração na formação dos enxames. Não existe correlação entre o número de operárias e machos nos ninhos $r_{\mathrm{s}}=0,009 \mathrm{~ns}, \mathrm{p}>0,05$, nem entre o número de machos $r_{s}=0,058 \mathrm{ris}, p>0,05$, e se chegam a estar relacionados em algum período do ciclo da colônia, é passageira, a causa de que os machos podem abandonar os ninhos, como sucede com os machos de Polistes e Mischocyttarus (West-Eberhard, 1969; Jeanne \& Castellón, 1980).

\section{Imaturos}

Os valores sobre a população de imaturos nos ninhos, estão na tabela 3 . A cria consiste de ovos, larvas e pupas. Ovos e larvas podem ser encontrados em células, nas quais as vespas estavam levantando as paredes, ou em células já usadas que apresentavam restos de seda e mecônio como evidência de haver sido usadas e eclodido um adulto, sendo reocupadas $\mathrm{com}$ ovos e larvas. As pupas encontravam-se em células com paredes totalmente construidas, não havendo nenhuma célula que apresentasse uma dupla disposição de mecônio ou dupla capa de seda, evidenciando ter sido usada mais de duas vezes anteriormente.

As pupas, ao serem analisadas, foram separadas como pupas jovens quando não era possível identificar o sexo pela contagem do número de escleritos abdominais em virtude do que estes estarem fundidos e pouco diferenciados e os apêndices eram pouco desenvolvidos. Pupas maduras apresentavam os apêndices desenvolvidos era possivel identificar o sexo pela contagem dos escleritos abdominais.

Não existem, nos ninhos, células especiais para reprodutores diferenciadas das células para operárias, como ocorre nos gêneros Vespa e Vespula. A distribuição de todas as castas nas células é irregular, se bem que é impossível distinguir morfologicamente as pupas como operárias e como rainha. Esta dificuldade de distinção se apresenta também entre operárias e rainhas em estágio adulto, sendo possível a sua distinção somente pela dissecção.

As larvas maduras, pupas e emergidos da primeira geração foram encontrados nas células mais centrais, o que confirma que foram estas as primeiras células a serem evopositadas, enquanto que ovos e larvas de primeiros estágios se encontravam distribuidos nas células mais periféricas dos ninhos.

Em ninhos maduros, as células mais centrais estavam reocupadas com ovos e larvas, enquanto que as células periféricas estavam ocupadas com pupas.

Os machos achados em estágio de pupas estavam sendo produzidos conjuntamente com as demais fêmeas da primeira geração, o que 
TABELA 3 - População total dos imaturos (ovos, larvas e pupas) dos 26 ninhos de S. surinama. Total de ovos e larvas correspondentes às quantidades deles na primeira e na segunda geração. Pupas jovens não apresentam apêndices desenvolvidos e é difícil identificar os sexos pela contagem dos segmentos abdo. minais em face de estes se encontrarem fundidos. Elas têm um grau de esclerotização baixo. Pupas maduras possuem apêndices desenvolvidos e os sexos são identificáveis pela contagem dos segmentos abdominais. Seu grau de esclerotização é maior que em pupas jovens.

\begin{tabular}{|c|c|c|c|c|c|c|}
\hline \multirow{2}{*}{ Ninho } & \multirow{2}{*}{ Total ovos } & \multirow{2}{*}{ Total larvas } & \multicolumn{3}{|c|}{$P \cup P A S$} & \multirow{2}{*}{ Total imaturos } \\
\hline & & & Jovens & Maduras & Total & \\
\hline 8 & 197 & 369 & 113 & 227 & 340 & 906 \\
\hline 19 & 183 & 349 & 0 & 0 & 0 & 532 \\
\hline 20 & 46 & 93 & 0 & 27 & 27 & 166 \\
\hline 21 & 77 & 105 & 2 & 43 & 45 & 227 \\
\hline 22 & 120 & 147 & 50 & 111 & 161 & 432 \\
\hline 23 & 295 & 232 & 0 & 1 & 1 & 619 \\
\hline 24 & 132 & 258 & 0 & 221 & 221 & 611 \\
\hline 25 & 133 & 115 & 12 & 217 & 229 & 477 \\
\hline 26 & 119 & 174 & 0 & 54 & 54 & 347 \\
\hline 27 & 232 & 320 & 65 & 194 & 259 & 811 \\
\hline 28 & 107 & 132 & 59 & 149 & 208 & 447 \\
\hline 29 & 11 & 8 & 0 & 0 & 0 & 19 \\
\hline 30 & 161 & 234 & 22 & 152 & 174 & 569 \\
\hline 31 & 101 & 81 & 86 & 188 & 274 & 457 \\
\hline 32 & 83 & 244 & 105 & 0 & 105 & 432 \\
\hline 33 & 251 & 363 & 118 & 0 & 118 & 732 \\
\hline 34 & 240 & 396 & 109 & 348 & 457 & 1071 \\
\hline 36 & 283 & 320 & 66 & 128 & 194 & 797 \\
\hline 37 & 113 & 296 & 171 & 72 & 243 & 652 \\
\hline 38 & 232 & 190 & 174 & 160 & 334 & 756 \\
\hline 39 & 67 & 167 & 53 & 93 & 146 & 380 \\
\hline 40 & 87 & 102 & 30 & 112 & 142 & 331 \\
\hline 41 & 103 & 152 & 5 & 18 & 23 & 278 \\
\hline 43 & 82 & 170 & 0 & 0 & 0 & 252 \\
\hline 44 & 20 & 21 & 2 & 20 & 22 & 63 \\
\hline 45 & 99 & 163 & 10 & 0 & 10 & 262 \\
\hline
\end{tabular}

indica que indistintamente desde o começo do ciclo do ninho alguns ovos ou larvas se desenvolvem em forma sexual macho, paralelamente com a produção de fêmeas.

PRODUTIVIDADE POR CÉLULA

De acordo com o item anterior, pode estimar-se a porceńtagem de ovos, larvas, pupas e emergidos que faz parte da primeira geração dos ninhos. Quando as células não apresentam restos de seda ou mecônio, diz-se que os indivíduos. desenvolvendo-se no seu interior, pertencem à primeira geração, os emergidos de células com uma camada de seda e mecônio também pertencem à primeira geração do ninho.

Em células com vestígios de seda e mecônio e reusadas com ovos e larvas, diz-se que os imaturos ali presentes são de segunda geração. $\mathrm{Na}$ tabela 4, apresentam-se os dados obtidos de célula em que houve produção de adultos da primeira geração e de células que estavam vazias ou reocupadas com ovos e larvas da segunda geração.

Em concordância com os dados apresentados nas tabelas $3 \in 4$, é possível calcular a porcentagem de produtividade das células para a primeira geração e das células reocupadas com imaturos da segunda geração. 
TABELA 4 - Número total das células no ninho, células usadas e vazias, células de emergidos e reusadas com ovos e larvas. Células usadas e vazias são células donde emergiu um adulto e não foram reusadas. Células já usadas apresentam restos de seda e mecônio.

\begin{tabular}{|c|c|c|c|c|}
\hline Ninho & $\begin{array}{c}\text { Número } \\
\text { total } \\
\text { das células }\end{array}$ & $\begin{array}{l}\text { Células } \\
\text { usadas } \\
\text { e vazias }\end{array}$ & $\begin{array}{l}\text { Células } \\
\text { ovos }\end{array}$ & $\begin{array}{r}\text { reusadas com } \\
\text { larvas }\end{array}$ \\
\hline 8 & 1056 & 0 & 197 & 369 \\
\hline 19 & 532 & 0 & 0 & 0 \\
\hline 20 & 187 & 21 & 30 & 38 \\
\hline 21 & 284 & 57 & 72 & 103 \\
\hline 22 & 442 & 10 & 46 & 27 \\
\hline 23 & 876 & 257 & 295 & 323 \\
\hline 24 & 617 & 6 & 44 & 92 \\
\hline 25 & 485 & 8 & 108 & 2 \\
\hline 26 & 347 & 0 & 0 & 0 \\
\hline 27 & 811 & 0 & 69 & 194 \\
\hline 28 & 358 & 11 & 52 & .84 \\
\hline 29 & 19 & 0 & 0 & 0 \\
\hline 30 & 583 & 4 & 103 & 109 \\
\hline 31 & 457 & 0 & 0 & 0 \\
\hline 32 & 432 & 0 & 0 & 0 \\
\hline 33 & 732 & 0 & 0 & 0 \\
\hline 34 & 1107 & 26 & 238 & 395 \\
\hline 36 & 797 & 0 & 254 & 300 \\
\hline 37 & 653 & 1 & 2 & 0 \\
\hline 38 & 861 & 5 & 232 & 190 \\
\hline 39 & 380 & 0 & 37 & 160 \\
\hline 40 & 335 & 4 & 1 & 0 \\
\hline 41 & 279 & 1 & 45 & 113 \\
\hline 43 & 252 & 0 & 0 & 0 \\
\hline 44 & 179 & 116 & 18 & 9. \\
\hline 45 & 272 & 0 & 0 & 0 \\
\hline
\end{tabular}

De acordo com Spradbery (1965), a produtividade pode expressar-se em diversas formas. Uma dessas formas é a medida do uso de células aproveitáveis, o que vem dado pela seguinte expressão:

$$
\begin{gathered}
\text { (Número de imaturos }+ \text { adultos } \\
\text { produzidos) } \times 100 \\
\text { número de células } \times 3
\end{gathered}
$$

e que vai indicar-nos a porcentagem da produtividade. A expressão foi usada inicialmente para colônias de Vespinae, onde o máximo ae produtividade é 3 vezes o número de células. Não é aplicado o valor 3 do denominador da expressão anterior, que indica uma terceira geração, sendo que se anula o mesmo para ajustar us resultados da produtividade real para os valores dos imaturos da primeira e segunda geração presentes nos ninhos de S. surinama; não teorizando para os indivíduos que possam ser produzidos depois apenas da segunda geração. Em todos os ninhos de $S$. surinama, foram encontrados imaturos de até segunda geração e nenhuma evidência de imaturos da terceira geração.

$\mathrm{Na}$ tabela 5 , mostram-se os valores das porcentagens de produtividades parciais para os estágios de ovos, larvas, pupas e emergidos de primeira e segunda geração e as porcentagens do total de imaturos produzidos por célula.

Para achar as porcentagens parciais, foi feito igual a zero o valor correspondente a adultos produzidos, considerando somente como imaturos o estágio do qual queria achar a porcentagem parcial, dividindo este vaior entre o número de células correspondentes a cada ninho e multiplicando o resultado por 100 . Por exemplo, 197 ovos/ 1056 células $\times 100=$ $18,65 \%$. Os resultados parciais para ovos, larvas, pupas e emergidos de um ninho somain-se entre si para achar-se os valores correspondentes da coluna dos imaturos. Por outro lado, a porcentagem de produtividade total de células era achado, ao somar-se os valores das porcentagens de imaturos com emergidos se presentes no ninho. Para achar a porcentagem de emergidos, foi dado o valor correspondente a imaturos igual a zero.

Existe relação devida ao resultado significativo, ao aplicar a análise de correlação de Spearmann (Sokal e Rolhf, 1969) entre as seguintes variáveis :

$$
\begin{array}{ll}
\text { operárias - ovos; } & r_{s}=0,60, \quad(p<0,01) \\
\text { operárias - larvas; } & r_{s}=0,67, \quad(p<0,01) \\
\text { operárias - pupas; } & r_{s}=0,32, \quad(p>0,05) \\
\text { operárias - imaturos; } & r_{s}=0,62,(p<0,01)
\end{array}
$$


TABELA 5 - Porcentagens parciais e totais da produtividade dos imaturos por células. Ovos e larvas da primeira geração encontram-se nas células que não apresentam restos de seda e mecônio. Ovos e larvas da segunda geração encontram-se nas células que apresentam restos de seda e mecônio. Pupas e emergidos (os adultos produzidos) pertencem à primeira geraçăo. Porcentagens de imaturos compreendem as porcentagens de ovos, larvas e pupas da primeira e segunda geração que conjuntamente com os emergidos dão a quantidade estimada da porcentagem total de produtividade de imaturos por células. A porcentagem total dividida por 100 dá a estimativa do uso por cada célula.

\begin{tabular}{|c|c|c|c|c|c|c|c|c|}
\hline \multirow[t]{2}{*}{ Ninho } & \multicolumn{2}{|c|}{$\begin{array}{l}\% \text { ovos } \\
\text { geração }\end{array}$} & \multicolumn{2}{|c|}{$\begin{array}{c}\text { \% larvas } \\
\text { geração }\end{array}$} & \multirow[t]{2}{*}{$\%$ pupas } & \multirow[t]{2}{*}{$\%$ imaturos } & \multirow[t]{2}{*}{$\%$ emergidos } & \multirow[t]{2}{*}{$\begin{array}{c}\text { Total da } \\
\text { produtividade }\end{array}$} \\
\hline & $10^{\circ}$ & $2^{\circ}$ & 1. & $2 .^{*}$ & & & & \\
\hline
\end{tabular}

\begin{tabular}{|c|c|c|c|c|c|c|c|c|}
\hline & & & & & 1 & & & \\
\hline 8 & 0 & 18,65 & 0 & 34,94 & 32,20 & 85.79 & 53,50 & 139,40 \\
\hline 19 & 34,40 & 0 & 65,60 & 0 & 0 & 100,00 & 0 & 100,00 \\
\hline 20 & 8,56 & 16,04 & 29,41 & 20,32 & 14,44 & 88,77 & 47,60 & 136,36 \\
\hline 21 & 1,76 & 25,35 & 0,70 & 36,26 & 15,84 & 80,00 & 81,69 & 161,69 \\
\hline 22 & 16,74 & 10,40 & 27,15 & 6,10 & 36,42 & 96,81 & 18,78 & 115,59 \\
\hline 23 & 0 & 33,68 & 0 & 36,87 & 0,11 & 70,66 & 99,80 & 170,53 \\
\hline 24 & 14,26 & 7,13 & 26,90 & 14,91 & 35,82 & 99,02 & 23,01 & 122,03 \\
\hline 25 & 5,15 & 22,27 & 23,29 & 0,41 & 47,22 & 98,34 & 24,33 & 122,67 \\
\hline 26 & 34,29 & 0 & 50,14 & 0 & 15,56 & 100,00 & 0 & 100,00 \\
\hline 27 & 20,10 & 8,50 & 15,54 & 23,92 & 31,94 & 100,00 & 32,43 & 132,43 \\
\hline 28 & 15,36 & 14,52 & 13.40 & 23,46 & 58,10 & 114,40 & 41,06 & 155,50 \\
\hline 29 & 57,89 & 0 & 42,10 & 0 & 0 & 100,00 & 0 & 100,00 \\
\hline 30 & 9,95 & 17,67 & 21,44 & 18,69 & 29,85 & 97,60 & 37,05 & 134,65 \\
\hline 31 & 22,10 & 0 & 17,72 & 0 & 60,00 & $99,8 \hat{2}$ & 0 & 99,82 \\
\hline 32 & 19,21 & 0 & 56,48 & 0 & 24,31 & 100,00 & 0 & 100,00 \\
\hline 33 & 34,28 & 0 & 49,60 & 0 & 16,12 & 100,00 & 0 & 100,00 \\
\hline 34 & 0,18 & 21,50 & 0,09 & 35,68 & 41,28 & 98,73 & 59,53 & 158,26 \\
\hline 36 & 3,64 & 31,87 & 2,50 & 37,64 & 24,34 & 99,99 & 69,51 & 169,50 \\
\hline 37 & 17,00 & 0,31 & 45,33 & 0 & 37,21 & 108,86 & 0,46 & 109,32 \\
\hline 38 & 0 & 26,95 & 0 & 22,07 & 38,79 & 87.81 & 49,60 & 137,41 \\
\hline 39 & 7,89 & 9,74 & 1,84 & 42,10 & 38,42 & 99.99 & 51,84 & 151,83 \\
\hline 40 & 25,67 & 0,30 & 30,45 & 0 & 42,39 & 98,81 & 1,50 & 100,31 \\
\hline 41 & 20,79 & 16,13 & 13,98 & 40,50 & 8,24 & 99,64 & 57,00 & 156,64 \\
\hline 43 & 32,54 & 0 & 67,46 & 0 & 0 & 100,00 & 0 & 100,00 \\
\hline 44 & 1,12 & 10,06 & 6,70 & 5,03 & 12,29 & 35,20 & 79,89 & 115,09 \\
\hline 45 & 36,40 & 0 & 59,92 & 0 & 3,68 & 100,00 & 0 & 100,00 \\
\hline
\end{tabular}

Mostra-se em geral uma tendência de os imaturos aumentarem, conforme aumenta a população de operárias. Igual tendência mostrase entre os imaturos e os emergidos. Esta tendência do aumento das operárias e emergidos indica uma relação entre a população adulta produzida periodicamente e os estágios imaturos durante este período o que indica também a relação entre a produtividade do nínho e a população adulta. Isto se evidencia ainda mais nos valores obtidos como resultado da aplicação de análises de correlação de Spearmann (Sokal e Rolhf, 1969) entre os emergidos e os diferentes estágios imaturos, cujos valores são os seguintes :

Emergidos e ovos, $\quad r_{s}=0,419,(p<0,05)$

Emergidos e larvas, $\quad r_{s}=0,338,(p<0,05)$

Emergidos e pupas, $\quad r_{s}=0,466, \quad(p<0,05)$

Emergidos e imaturos, $r_{s}=0,447,(p<0,05)$ 
PRODUÇÃO DE MACHOS

Alguns autores (Spradbery, 1965; Richards, 1971) asseguram que os machos das vespas são produzidos por ovos haplóides não fecundados e ovopositados por operárias em espécies monogínicas. Em colônias de espécies poligínicas é bastante difícil observar-se na natureza esta ovoposição por parte das operárias dada a presença do invólucro no ninho. Simões (1977) em seu estudo com Polybia exigua e Stelopolybia pallipes não observou ovoposição por parte das operárias.

Em S. surinama, há evidências baseadas ao coletar os 26 ninhos com diferentes idades pe. ríodos estimadas e na análise da população de adultos e imaturos, que os primeiros machos que emergem são produtos da ovoposição por parte de fêmeas fecundadas (ver tabela 3) porque todas as operárias dissecadas não apresentavam ovários desenvolvidos ou semi-desenvolvidos.

Em espécies poligínicas, acredita-se que a produção de machos ocorre no final do ciclo da colônia, assim como a produção de novas rainhas para formar os enxames.

Das 26 colônias, 9 apresentam uma idade período estimada em menos que $1,00 \mathrm{sem}$ presença de machos, 17 são superiores em 1,60 idade periodo estimada e das quais 6 não apresentam machos e 11 apresentam.

Admite-se que a cópula entre machos e reproductoras em $S$. surinama e possivelmente em outras espécies poligínicas ocorre antes da migração do enxame. Existem evidências que c comprovam, tal como a ausência de machos nos enxames (Richards \& Richards, 1951) e a cópula fracassada dos machos que é dificultada ou impossibilitada dado o repúdio por parte das operárias e que provavelmente não teriam êxito com as rainhas do ninho pela proteção que as operárias oferecem.

$\mathrm{Na}$ tabela 6 , é dado o número de pupas machos, a porcentagem destas pupas machos em relação ao total de pupas no ninho, o número total de machos adultos em cada ninho e sua porcentagem em relação à população total de adultos e o número total de machos. O ninho 32 apresenta um macho em sua população adulta sendo que todas as células do ninho estavam ocupadas com ovos, larvas e pupas da

TABELA 6 - Número de pupas machos (PM) e porcentagem das pupas machos em relação ao número total de pupas (\% PM/TP). Número dos machos adultos (MA), porcen. tagem de machos adultos com relação ao número total de adultos ( $\% \mathrm{MA} / \mathrm{TA})$, número total de machos (TM).

\begin{tabular}{|c|c|c|c|c|c|}
\hline Ninho & PM & $\% \mathrm{PM} / \mathrm{TP}$ & MA & $\% \mathrm{MA} / \mathrm{TA}$ & TM \\
\hline 8 & 6 & 1,76 & 0 & 0 & 6 \\
\hline 19 & 0 & 0 & 0 & 0 & 0 \\
\hline 20 & 0 & 0 & 0 & 0 & 0 \\
\hline 21 & 1 & 2,22 & 0 & 0 & 1 \\
\hline 22 & 4 & 2,48 & 0 & 0 & 4 \\
\hline 23 & 0 & 0 & 21 & 5,06 & 21 \\
\hline 24 & 0 & 0 & 0 & 0 & 0 \\
\hline 25 & 0 & 0 & 0 & 0 & 0 \\
\hline 26 & ? & 0 & 0 & 0 & 0 \\
\hline 27 & 0 & 0 & 0 & 0 & 0 \\
\hline 28 & 1 & 0,93 & 1 & 0,43 & 2 \\
\hline 29 & 0 & 0 & 0 & 0 & 0 \\
\hline 30 & 0 & 0 & 0 & 0 & 0 \\
\hline 31 & 0 & 0 & 0 & 0 & 0 \\
\hline 32 & 0 & 0 & $1^{*}$ & 0,49 & $1^{*}$ \\
\hline 33 & 0 & 0 & 0 & 0 & 0 \\
\hline 34 & 0 & 0 & 0 & 0 & 0 \\
\hline 36 & 7 & 3,60 & 7 & 2,75 & 14 \\
\hline 37 & 2 & 0,82 & 0 & 0 & 2 \\
\hline 38 & 35 & 10,48 & 57 & 9,28 & 92 \\
\hline 39 & 0 & 0 & 1 & 0,53 & 1 \\
\hline 40 & 0 & 0 & 0 & 0 & 0 \\
\hline 41 & 15 & 65,22 & 31 & 24,03 & 46 \\
\hline 43 & 0 & 0 & 0 & 0 & 0 \\
\hline 44 & 0 & 0 & 1 & 1,10 & 1 \\
\hline 45 & 0 & 0 & 0 & 0 & 0 \\
\hline
\end{tabular}


primeira geração, não existindo nenhuma célula ccm restos de seda ou mecônio, vazia ou reusada. A idade período estimada deste ninho é de 0,692 , o que indica a imaturidade da colônia e também uma anormalidade pela presença do macho porque, no ninho, ainda não havia ocorrido emergência de adultos.

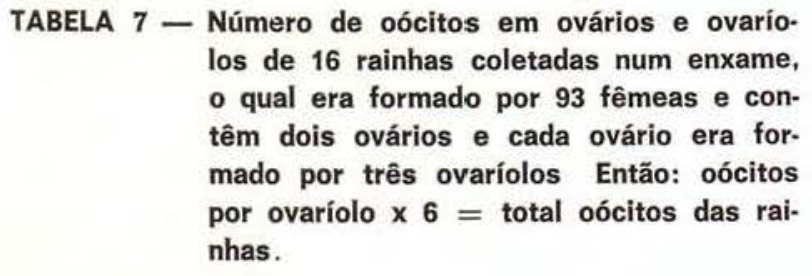
los de 16 rainhas coletadas num enxame, o qual era formado por 93 fêmeas e contêm dois ovários e cada ovário era formado por três ovaríolos Então: oócitos por ovaríolo $\times 6=$ total oócitos das rainhas.

\begin{tabular}{llll}
\hline Rainha & $\frac{\text { Oócitos }}{\mathrm{p} / \text { ovaríolo }}$ & $\frac{\text { Oócitos }}{\mathrm{p} / \text { ovário }}$ & Total oócitos \\
\hline
\end{tabular}

\begin{tabular}{cccc} 
A & 7 & 21 & 42 \\
B & 6 & 18 & 36 \\
C & 8 & 24 & 48 \\
D & 9 & 27 & 54 \\
E & 6 & 18 & 36 \\
F & 7 & 21 & 42 \\
G & 7 & 21 & 42 \\
H & 7 & 21 & 42 \\
I & 9 & 27 & 54 \\
J & 8 & 24 & 48 \\
K & 8 & 24 & 48 \\
L & 7 & 21 & 42 \\
M & 7 & 21 & 42 \\
N & 8 & 24 & 48 \\
O & 8 & 24 & 48 \\
P & 9 & 27 & 54 \\
\hline Total oócitos & no enxame & & 726 \\
\hline
\end{tabular}

\section{DISCUSSÃo}

Em Polybiini, há a presença de múltiplas rainhas que fazem parte dos enxames (poliginia), as quais são as reprodutoras encarregadas da ovoposição no ninho. Muito provavelmente, é uma estratégia para a conservação da espécie e garantia de reproduçăo.
$\mathrm{Na}$ tabela 1 , observa-se o número de rainhas por colônias em 26 ninhos de $S$. surinama. as quais variam em número nos diferentes ninhos. Todas as rainhas estavam fecundadas $e$ com ovários bem desenvolvidos. A média de ovos por ovários das rainhas nos ninhos expõese na tabela 1 , não se achando nenhuma operária com os ovários desenvolvidos ou fertilizados. West-Eberhard (1973) não achou em nenhuma de suas dissecções operárias com ovos maduros presentes nos ovários ou com algum grau de desenvolvimento dos ovários que sugerissem ovoposição por parte das mesmas.

West-Eberhard (1973) mostrou fatos evidentes de monoginia periódica nas especies poligínicas Metapolybia docilis e $M$. aztecoides e sugeriu que o ciclo da colônia em Metapolybia podia ser: Fundação do ninho por um enxame políginico ou monogínico, redução no número das rainhas da colônia a uma; morte, desaparecimento ou senilidade reprodutiva da única rainha para posteriormente rainhas filhas (emergidas posteriormente) ovopositarem no ninho parental e finalmente multipiicação da colônia por produção de enxame, permanecendo algumas vespas filhas no ninho mãe.

Igual fenômeno apresenta-se com clareza em S. surinama, de acordo com os dados obtidos pelas análises das colônias e ninhos, cujas evidências são apresentadas a seguir :

I - Presença de uma única rainha em quatro (4) ninhos (2 ninhos jovens e 2 maduros). sugere monogínia nas colônias desta espécie poligínica. Nirhos de espécies poligínicas como Metapolybia cingulata, Polybia micans, $P$. bistriata, P. bicyttarella, P. catillifex foram citados por Richards \& Richards (1951) com uma única rainha. Em outras espécies como Polybia chrysotorax e $P$. occidentalis foi achada também uma única rainha no ninho, evidenciando momoginia (West-Eberhard, 1973);

II - Ausência de rainhas no ninho 20 (ninho maduro) Tabela 4, 166 imaturos e 12 operárias jovens sugere também o desaparecimento das rainhas do ninho e permanência de operárias jovens recentemente emergidas das células. Este ninho não apresentcu evidências de ataques que tenham sido a causa do desaparecimento dos aduitos; 
III - Presença de duas até 59 rainhas em 21 ninhos mostrando a poliginia. Destes 21 ninhos, 6 foram classificados como jovens com uma idade periodo estimada inferior a 1 de acordo com a fórmula de Richards \& Richards (1951);

IV - Em 9 ninhos, o número de adultos emergidos foi maior que o número de adultos achados no ninho. Estes resultados podem interpretar-se de duas formas. (a) Existiu uma alta mortalidade à predação nesses ninhos, enquanto que em outros 9 ninhos o número de eclodidos foi maior que os adultos dos ninhos, e nos quais então não existiu cu existiu pouca predaçăo. Esperar-se-ia que igual predação acontecesse com todas as colônias pelo fato de os ninhos com colônia terem sido coleta dos na mesma área. (b) A outra interpretação é que depois que as colônias produziram os adultos, houve formação de enxame e migração ficando no ninho algumas rainhas e operárias, como evidencia a tabela 5. Estas rainhas e operárias mantêm o ninho velho para a produção de novos adultos e formação de um segundo ou mais enxames. Zikam (1951, em Richards \& Richards, 1951) observou uma colônia de S. surinama por 15 anos e Richards (1971) opinou que parece ser que estas colônias usualmente não crescem indefinidamente. Pude observar uma colônia de $S$. surinama por mais de 18 meses na sede do INPA sem que houvesse crescimento do ninho. Estas observações confirmam ainda mais a idéia de formação de enxames periódicos em S. surinama, inclinando-me a aceitar de fato a segunda evidência (formação de enxame) mais que a primeira (predação) .

A produtividade do ninho é uma medida da eficiencia da colônia para produzir os novos indivíduos que vão contribuir para o êxito da espécie. Esta produtividade aumenta à medida que aumenta a idade da colônia.

A eficiência da colônia, de acordo com Richards (1971) é dada pelo crescimento das colônias e seu sucesso reprodutivo, e Spradbery $(1965,1975)$ opinou que a eficiência reprodutiva está limitada por fatores como o número de células, os ovos que abastecem estas células, clima (em colônia de clima temperado) e predaçăo nos trópicos.
A produtividade da colônia está associada estreitamente com o número das operárias no ninho. Análises de correlação entre operárias de $S$. surinama com cada um dos estágios (ovo larva e pupa) de desenvolvimento da cria e $\mathrm{ccm}$ as rainhas deu um resultado significativo igualmente entre operárias e adultos produzidos. Estes resultados evidenciam o sucesso da colônia para produzir a cria e posterior formação de enxames periódicos nos ninhos, como resultado de estratégias para a disseminação da espécie e esforço reprodutivo.

Fatores do ninho e da colônia servem para avaliar o sucesso reprodutivo como são: Número de ovos por ovários ou ovaríolos por uma rainha, número de células construídas por operárias (em Polybiini), utilização e reutilização de células, número de adultos produzidos e número de operárias nos ninhos, número de machos e rainhas produzidos em cada colônia. Estes fatores ainda são pouco conhecidos em Polybiini, e são necessárias mais informações.

Trabalhos destes aspectos são tratados amplamente por Richards \& Richards (1951) Brian \& Brian (1952), Micherier (1953, 1964), Spradbery $(1965,1975)$ e Wilson (1974).

\section{CONCLUSÕES}

Em concơrdância com os dados proporcionados por Richards \& Ricahrds (1951) para Metapolybia cingulata, Polybia micans, P. bistrata P. bicyttarella, P. catillifex e West-Eberhard (1973) para de Metapolybia docilis e $M$. aztecoides, em cujos nirihos encontraram a presença de uma rainha, foi encontrada também essa mesma condiçăo em quatro ninhos de $S$. surinama. Dessa forma, pode-se concluir que existem períodos alternados de "poliginia" — "monoginia" na espécie. Nesta condição, é possivel uma estratégia para a preservação da espécie que permite uma agregação periódica e posterior migração de vários indivíduos da colônia juntamente com um ou vários indivíduos da colônia juntamente com uma ou várias rainhas, como resposta à pressão exercida pe. los inimigos naturais da espécie e que promove o incremento e desenvolvimento das colônias

Existem evidências que sugerem a formação de enxames periódicos produzidos em ninhos de $S$. surinama. Isto é, o desaparecimento 
de rainhas, presença de operárias jovens e ausência das operárias velhas em algum ninho e o déficit de emergidos com relação ao número total de adultos na colônia.

Provavelmente, o ciclo da colônia em ninhos de S. surinama é :

a) Chegada do enxame monogínico e poligínico;

b) monoginia periódica no ninho;

c) produção de rainhas, operárias e machos, que substituem a população pioneira;

d) migrações;

e) produção de novos indivíduos no ninho;

f) migração que pode resultar no abandono total do ninho.

\section{AGRADECIMENTOS}

Quero manifestar o meu agradecimento às pessoas e entidades que colaboraram para a realização deste trabalho: CNPq, INPA, MPEG, FUA; Drs. W. E. Kerr, P. E. Vanzolini, R. L. Jeanne. As Srtas. Violeta e Erica Hagmann, da Fazenda Taperinha, ao Capitão e tripulação do barco Victoria II, e ao colega Miguel Petrere Junior.

\section{SUMMARY}

Data on male, female and immature production during the first and second generation and analysis of nests which have a deficiency in number of emerged adults, indicating a possible migration or the formation of periodical swarms are presented. Evidences of monoginic-polyginic cicles are discussed here.

These subjects studied make up a series of alternate strategies adopted by $\mathbf{S}$. surinama to insure and guarantee that the production of new individuals and their dispersion is sucessful, as a counter to pressures from predators, parasites and Nature, insuring in this manner the survival of the species.

\section{BIBLIOGRAFIA}

AKRe, R.D.; Garnet, W.B.; MAcDonald, J.F.; Greene, A. \& LANDOLT, P.

1976 - Behavior and colony development of Ves. pula pennsylvannica and $\mathbf{V}$. atropilosa $(\mathrm{Hy}$ menoptera: Vespidae). J. Kans. Entomol. Soc., 49 (1): 63-84.

BRIAN, M.V. \& BRIAN, A.D.

1952 - The wasp, Vespula sylvestris Scop.: Feeding, foraging and colony development. Trans. R. Ent. Soc. Lond., 103 (1): 1-26.
GoввI, N.

1975 - Aspectos evolutivos da bionomia das vespas, visualizados através de estudos de reproduçāo (Hymenoptera: Aculeata), Dissertaçăo de Mestrado não publicada. Faculdade de Medicina, Ribeirão Preto, Universidade de São Paulo, USP, $X+88 p$.

JEANNE, R.L.

1972 - Social biology of the neotropical wasps Mischocyttarus drewseni. Bull. Mus. Com. Zool., 144 (3): 63-150.

JeANNE, R.L. \& CASTELlón, E.G.

1980 - Reproductive behavior of a male Neotropical social wasp, Mischocyttarus drewseni (Hymem: Vespidae). J. Kans. Entomol. Soc., 53 (2): 271-276.

MICHENER, C.D.

1953 - Reproductive efficiency in relation to the colony size in Hymenopterous societes. Insectes sociaux, 11 (4): 317-342.

1964 - Problems in the development of social behavior and communications among insects. Trans. Kans. Acad. Sci., 56: 1-15.

RICHARDS, O.W.

1971 - The biology of the social wasps (Hym.: Vespidae). Biol. Rev. 46: 483-528.

RICHARDS, O.W. \& RICHARDS, M.J.

1951 - Observations on the social wasps of South America (Hymenoptera: Vespidae). Trans.

SIMÕES, D. R. Ent. Soc. Lond., 102 (1): 1-169.

1977 - Etologia e diferenciação de casta em algumas vespas sociais (Hymenoptera: Vespidae). Tese de Doutoramento não publicada. Faculdade de Medicina, Ribeirão Preto. Universidade de São Paulo, 182p.

SOKAL, R.R. \& ROHLF, F.J.

1969 - Biometry. W. H. Freeman and Co. San Francisco. XIII $+548 p$.

SPRADBERY, J.P.

1965 - The social organization of wasps communities. Sym. Zool. Soc. London., 14: 61-96.

1975 - Seasonal changes in the population structure of wasps colonies (Hym.: Vespidae). Anim. Ecol., 40: 501-523.

WEST-EBERHARD, M.J.

1969 - The social biology of Polistine wasps. Misc. Publ. Mus. Zool. Univ. Michigan, 140: 1-101.

1973 - Monogyny in "polygynous" social wasps. Proc. VII Congr. IUSSI, London.

1975 - Estudios de las avispas sociales (Hymenoptere: Vespidae) del Valle del Oauca. 1. Objetivos, métodos y notas para facilitar la identificación de las especies comunes. Cespedesia 4 (16): 245-265.

WILSON, E.O.

1974 - The insect Societies. Harvard Univ. Press. Cambridge, Mass. $\mathrm{X}+548 \mathrm{p}$.

(Aceito para publicação em 16/06/80) 